\title{
Aerodynamic Effects of a 24-Foot, Multisegmented Telescoping Nose Boom on an F-15B Airplane
}

\author{
Stephen B. Cumming ${ }^{*}$, Mark S. Smith ${ }^{\dagger}$, and Michael A. Frederick ${ }^{*}$ \\ NASA Dryden Flight Research Center, Edwards, California, 93523
}

\begin{abstract}
An experimental multisegmented telescoping nose boom has been installed on an F-15B airplane to be tested in a flight environment. The experimental nose boom is representative of one that could be used to tailor the sonic boom signature of an airplane such as a supersonic business jet. The nose boom consists of multiple sections and could be extended during flight to a length of $24 \mathrm{ft}$. The preliminary analyses indicated that the addition of the experimental nose boom could adversely affect vehicle flight characteristics and air data systems. Before the boom was added, a series of flights was flown to update the aerodynamic model and characterize the air data systems of the baseline airplane. The baseline results have been used in conjunction with estimates of the nose boom's influence to prepare for a series of research flights conducted with the nose boom installed. Data from these flights indicate that the presence of the experimental boom reduced the static pitch and yaw stability of the airplane. The boom also adversely affected the static-position error of the airplane but did not significantly affect angle-of-attack or angle-of-sideslip measurements. The research flight series has been successfully completed.
\end{abstract}

$\begin{array}{ll}\text { CFD } & =\text { computational fluid dynamics } \\ C_{l_{r}} & =\text { rolling moment coefficient due to nondimensional yaw rate } \\ C_{l_{\beta}} & =\text { rolling moment coefficient due to angle of sideslip, } \mathrm{deg}^{-1} \\ C_{L_{\alpha}} & =\text { lift coefficient due to angle of attack, } \mathrm{deg}^{-1} \\ C_{m_{q}} & =\text { pitching moment coefficient due to nondimensional pitch rate } \\ C_{m_{\alpha}} & =\text { pitching moment coefficient due to angle of attack, } \mathrm{deg}^{-1} \\ C_{n_{d a}} & =\text { yawing moment coefficient due to aileron, } \mathrm{deg}^{-1} \\ C_{n_{r}} & =\text { yawing moment coefficient due to nondimensional yaw rate } \\ C_{n_{\beta}} & =\text { yawing moment coefficient due to angle of sideslip, } \mathrm{deg}^{-1} \\ C_{Y_{\beta}} & =\text { side force coefficient due to angle of sideslip, deg } \\ \text { deg } & =\text { degree } \\ g & =\text { gravitational acceleration, } 32.2 \mathrm{ft} / \mathrm{s}^{2} \\ \text { GPS } & =\text { global positioning system } \\ \text { INS } & =\text { inertial navigation system } \\ \text { POPU } & =\text { push-over-pull-up } \\ \alpha & =\text { angle of attack, deg } \\ \beta & =\text { angle of sideslip, deg }\end{array}$

\footnotetext{
${ }^{*}$ Aerospace Engineer, Aerodynamics Branch, P.O. Box 273/2228, and AIAA Member.

${ }^{\dagger}$ Aerospace Engineer, Aerodynamics Branch, P.O. Box 273/2228.

* Aerospace Engineer, Aerodynamics Branch, P.O. Box 273/2228.
} 


\section{Introduction}

A $\mathrm{n}$ interest in sonic boom reduction has recently increased in both the academic environment and aerospace industry. Commercial aircraft manufacturers are interested in producing passenger aircraft that are allowed to fly supersonically over inhabited landmasses. One way of reducing the sonic boom signature of an aircraft is to tailor the forebody shape of the vehicle as part of an integrated boom reduction airplane design. In conjunction with other tests and analyses, an experimental nose boom based on such a principle was installed on a NASA F-15B airplane (McDonnell Douglas Aerospace, now Boeing, St. Louis, Missouri), tail number 836, so that it could be tested in a flight environment. The flight test of the F-15B airplane with the boom attached provided valuable information for structural and mechanical design and the opportunity to evaluate the ability of the boom to affect the shock structure.

The addition of the experimental nose boom resulted in a unique configuration for the F-15B airplane. The experimental boom is significantly larger than a standard flight test nose boom and is multisegmented. This unique configuration necessitated analyses from various disciplines. A major concern throughout the initial stages of the project was the potential effects of the boom on the vehicle flight characteristics. Possible detrimental effects on the vehicle air data systems also were a concern. This report discusses the research conducted to predict and quantify the aerodynamic effects of the experimental nose boom on the F-15B airplane.

\section{Vehicle and Test Article Description}

The NASA F-15B airplane is a two-seat version of the F-15 airplane, an air-superiority fighter built by McDonnell Douglas Aerospace. The airplane is powered by two Pratt \& Whitney (West Palm Beach, Florida) F100-PW-100 turbofan engines with afterburners. Primary flight control surfaces consist of ailerons, twin rudders, and stabilators. The stabilators are used symmetrically for pitch control and differentially for roll control. Figure 1 shows the airplane in a standard flight configuration.

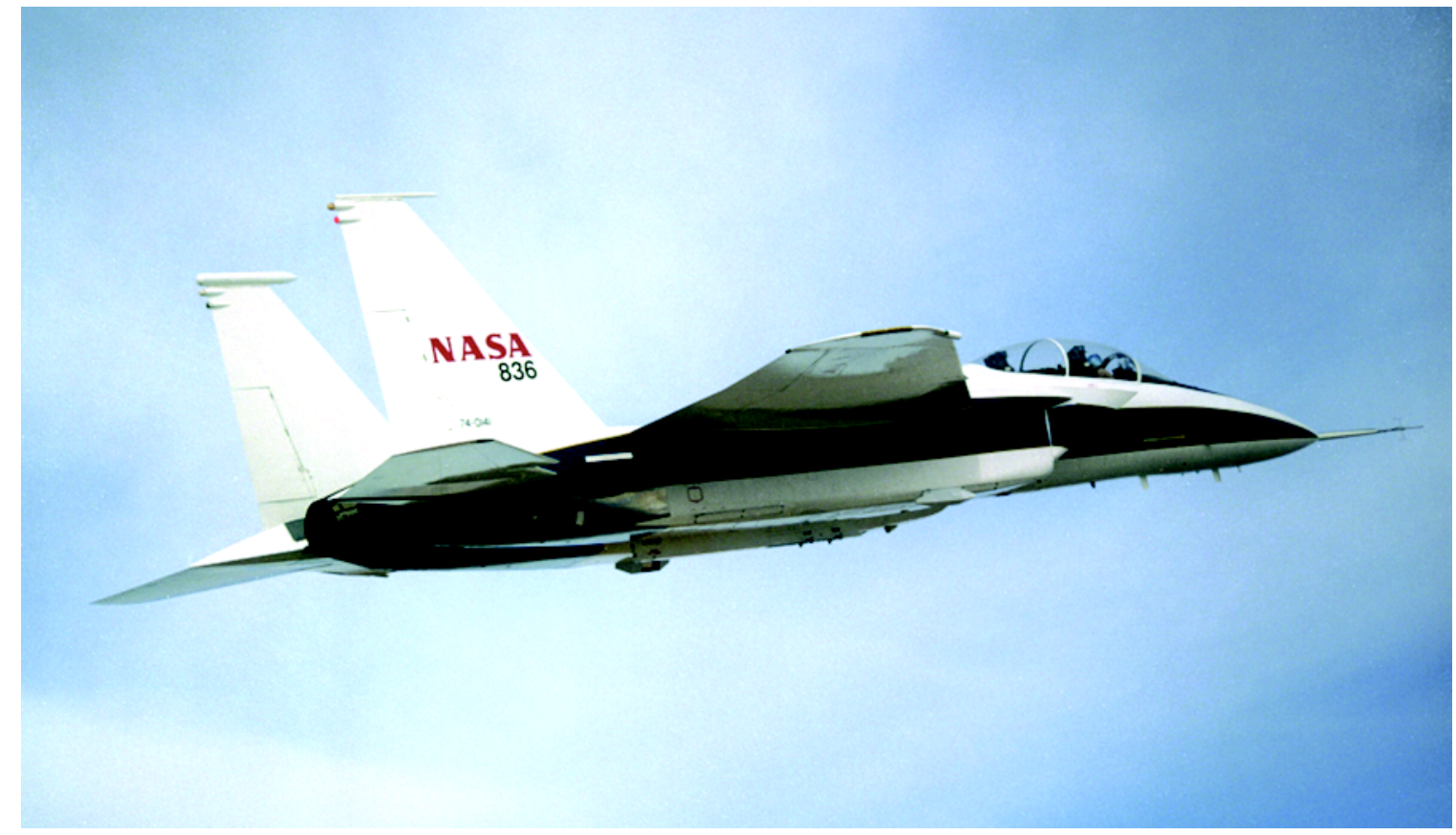

Figure 1. Baseline F-15B airplane.

The test F-15B airplane has been used extensively as a research test bed. ${ }^{1,2,3}$ The aircraft configuration often has been modified by the addition of a ventral store at its centerline station. Aerodynamic effects resulting from these modifications typically are estimated through comparisons with standard F-15B centerline stores. Installation of the oversized experimental nose boom, however, significantly altered the nose geometry of the airplane and resulted in a unique research configuration.

The experimental nose boom was designed and manufactured by Gulfstream Aerospace Corporation (Savannah, Georgia) for the Quiet Spike ${ }^{\mathrm{TM}}$ project. The boom was designed to attach to the F-15B airplane along with a 
composite radome. The composite radome was designed to match the basic curvature of the production radome and provide a smooth transition to the experimental nose boom. The resulting boom is approximately a half-scale version of one that could be used as part of an integrated airplane design for a supersonic business jet. The boom is extendible and consists of multiple cylinders and frustums. In the fully extended configuration, the boom consists of three cylindrical elements, two frustums, and a nose cone. The fully extended length is $24 \mathrm{ft}$. Figure 2 shows the nose boom in the extended configuration. The boom was attached to a new radome that substituted for the vehicle's standard flight test radome, which normally holds a standard NACA-style flight test nose boom.

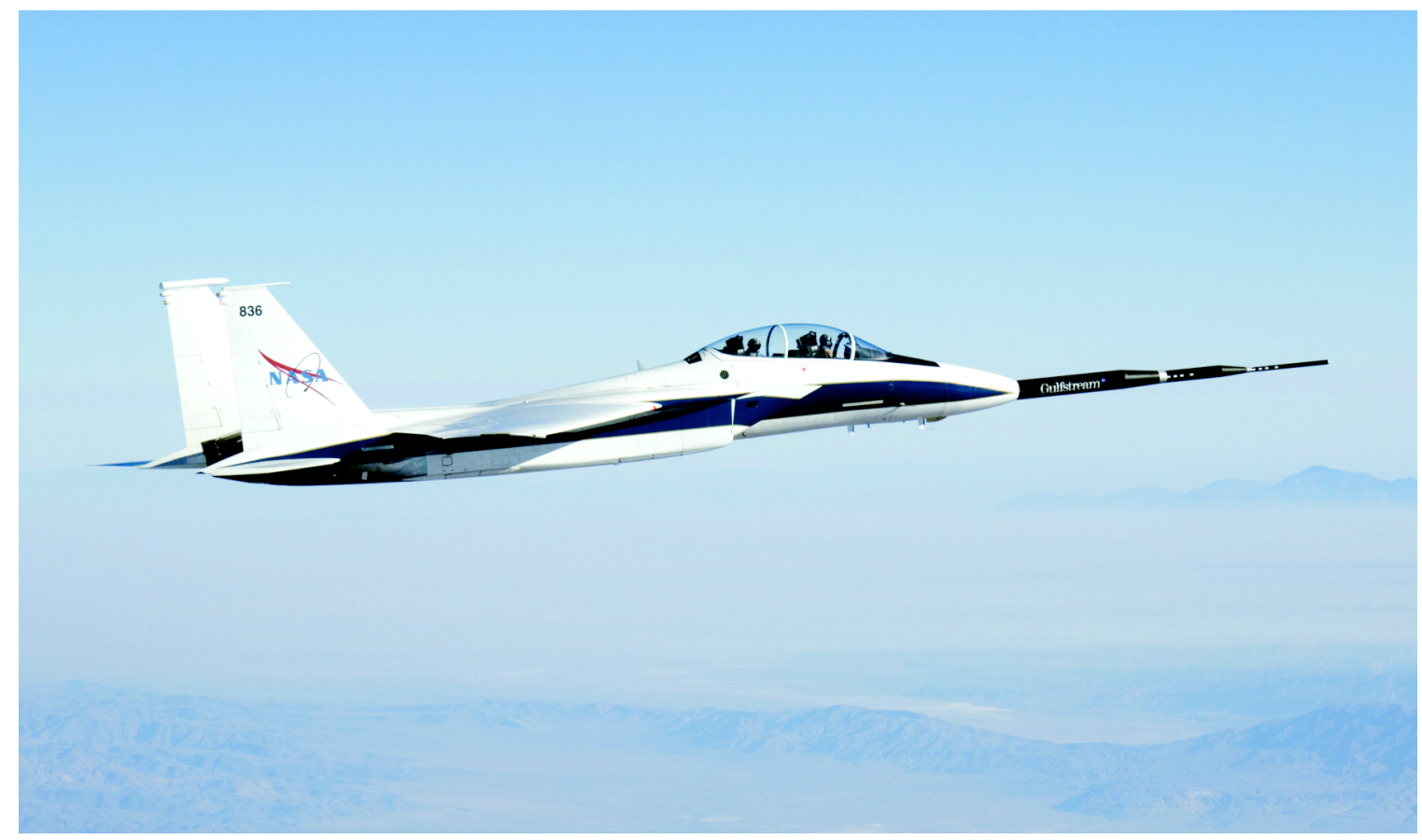

Figure 2. F-15B airplane with experimental nose boom.

Because the standard flight test nose boom had been removed, another method for determining research air data was necessary. Standard F-15B air data systems were instrumented to provide air data measurements suitable for research. Aircraft total and static pressure measurements were obtained by placing pressure transducers in the production pitot and static lines of the airplane. The total pressure was measured from the pneumatic line connecting both of the production pitot ports, whereas the static pressure was measured from the pitot-static probe on the starboard side of the airplane. Angle of attack was measured by the production angle-of-attack cone on the port side of the airplane. Pitot-static and angle-of-attack measurements were corrected using the source error corrections for the F-15 air data system. Because the F-15B airplane has no angle-of-sideslip measurement, a vane was mounted on a standoff attachment at the bottom of the airplane, just aft of the radome and forward of the Tactical Air Navigation blade antenna. Figure 3 shows the vane and standoff attachment. The addition of the vane was the only external modification to the airplane aside from the addition of the experimental nose boom. 


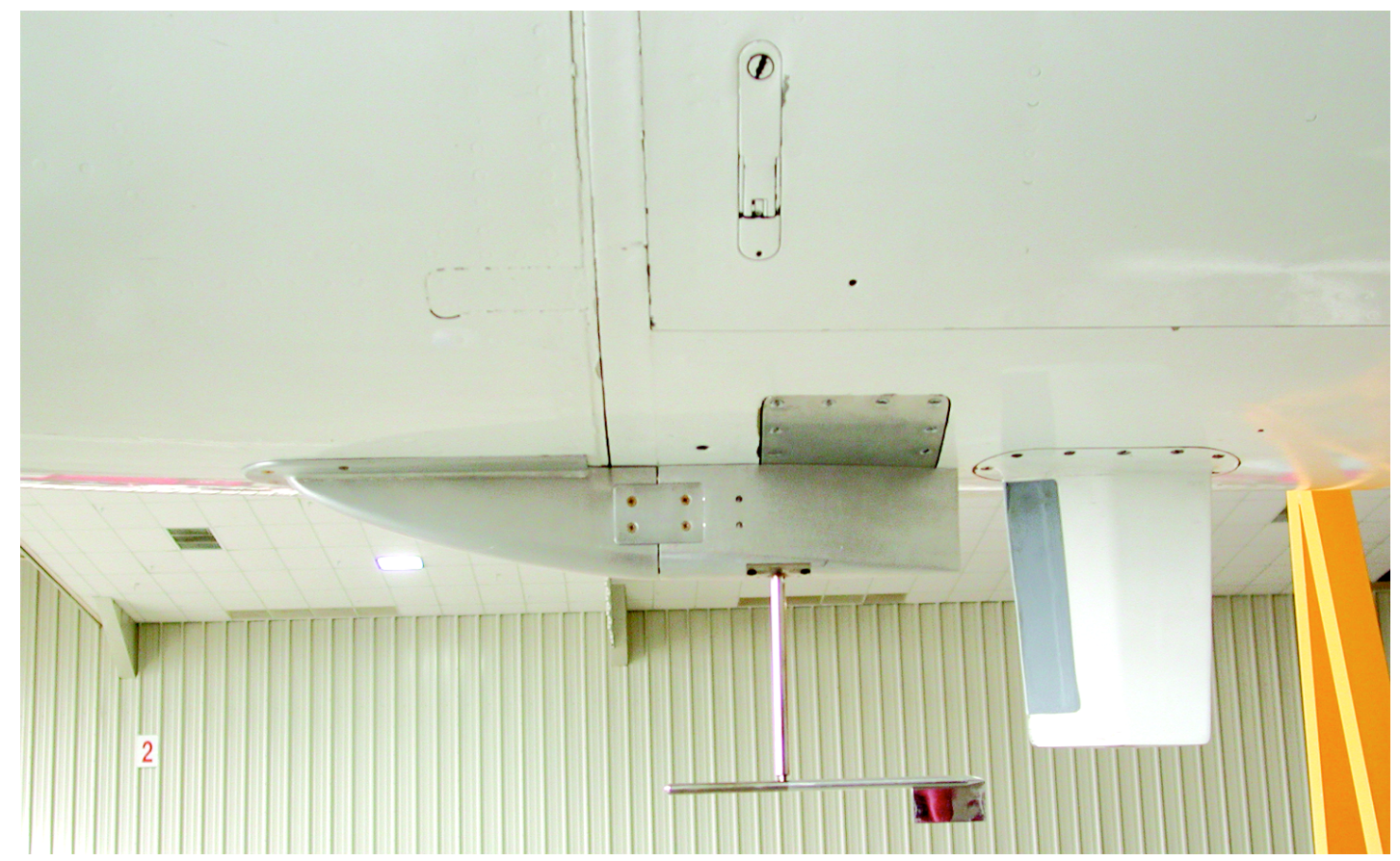

Figure 3. Fuselage sideslip vane.

Supplemental instrumentation was added to the airplane to support the flight tests. String potentiometers were used to measure surface deflections for the right aileron, left and right rudders, and left and right stabilators. Because the left and right ailerons are commanded to the same magnitude, the measurement of only one of them was assumed to be sufficient. String potentiometers also were used to measure stick and rudder pedal position. A unit consisting of a global positioning system (GPS) and inertial navigation system (INS) provided angular rates, aircraft attitude, and accelerations. A differential GPS provided precise geometric altitude measurements.

\section{Preliminary Analyses}

Significant aerodynamic analyses were performed prior to any flights conducted with the oversized nose boom, because any effects that the boom would have on the F-15B airplane were not known. Because of the size of the boom and its location in front of the airplane center of gravity, the experimental nose boom was predicted to negatively impact vehicle stability. A concern was that reductions in stability would be particularly significant at high speeds when the baseline airplane already exhibits low stability. Several techniques were used to estimate the effects of the experimental nose boom, including Euler computational fluid dynamics (CFD), vortex lattice methods, empirical data, and engineering methods.

The CFD analyses served to provide data on multiple aspects of the nose boom's influence. Gulfstream Aerospace Corporation used Euler CFD analysis, supplemented with empirical data on cone-cylinders, to estimate the forces and moments associated with the experimental nose boom. Euler CFD analysis also was used to predict the effect of the nose boom on near-field shock waves. These analyses concentrated on predicting flight loads on the nose boom, as well as predicting the effects of the nose boom on the shock signature of the airplane.

Desktop Aeronautics, Inc. (Palo Alto, California), performed Euler CFD of the F-15B airplane with and without the experimental nose boom. This analysis concentrated on the effects of the nose boom on the aerodynamic characteristics of the F-15B airplane. The data were used to estimate the changes in forces and moments resulting from the experimental nose boom, and those estimates were used to predict changes in the aircraft stability derivatives.

While the more complex CFD analyses were in progress, some less involved methods were used to estimate the effects of the experimental nose boom on aircraft stability and control. For subsonic flight conditions, vortex lattice panel methods were used. This method used a reasonable approximation of the actual geometry of the experimental nose boom and was supplemented with data from Hoerner. ${ }^{4}$ For supersonic flight conditions, data from reference 4 were used in conjunction with other empirical data from Ref. 5. A simplified nose boom geometry was used for the 
supersonic analysis. In addition to the modeling work, general research was conducted on cone-cylinder-frustum configurations in various flow fields.

\section{Flight Test Approach}

Two series of flight tests were completed. The first series was performed to obtain baseline data on the F-15B airplane with a standard air data nose boom, and the second series was flown with the experimental nose boom installed. A total of 34 flights were flown in support of this project, consisting of 4 baseline and 30 research flights. Following the research flight phase, the airplane was restored to the baseline configuration. Two additional flights were then performed to gather supplementary parameter estimation maneuvers.

\section{A. Baseline Flights}

The first series of flights, known as the baseline flights, consisted of four sorties flown with the F-15B airplane in a baseline configuration. The purpose of this flight series was to update the existing aerodynamic model for the airplane without the experimental nose boom. Part of the characterization involved calibrating the production air data system to replicate the more accurate data produced by the standard air data boom typically flown on the research airplane. This calibration was necessary for later flights when the air data boom would not be available. The baseline configuration included the additional sideslip vane, so it also was calibrated during this flight phase. Characterization of the airplane flight characteristics also was performed to update existing aerodynamic models.

Test conditions for the baseline flights were chosen to provide data that could be used for expansion of the flight envelope for the research flight phase. Several series of doublets were flown for parameter estimation purposes. For air data calibration, push-over-pull-up (POPU) maneuvers, wings-level rudder sweeps, constant-altitude accelerations, and constant-altitude decelerations were flown. The maneuvers associated with parameter estimation and air data calibration are known as aerodynamics maneuvers.

\section{B. Research Flights}

The second series of flights, known as the research flights, was performed with the experimental nose boom installed on the airplane. The purpose of this flight series was to provide flight data to assist in further Quiet Spike development. A total of 30 flights were flown during this flight series. For flight safety purposes, a flight envelope expansion plan was developed to incrementally expand the envelope of the modified F-15B airplane. This plan provided an interdisciplinary approach that expanded the envelope while incrementally exploring the various areas of concern for the flight tests, including structural loads, flutter, stability and control, and air data. This report focuses on the stability and control and air data portions of the envelope expansion.

Maneuver sets similar to those flown during the baseline flights were flown during the research flights. Figure 4 shows the research flight envelope and flight conditions in which parameter estimation maneuvers were flown for both the baseline and research flight series. Figure 4 also includes test points from the two flights that were conducted after the F-15B airplane was restored to the baseline configuration. Figure 5 indicates the flight conditions in which air data calibration maneuvers were flown for both flight phases. As these figures indicate, the envelope was much more fully characterized during the research flights than during the baseline flights. 

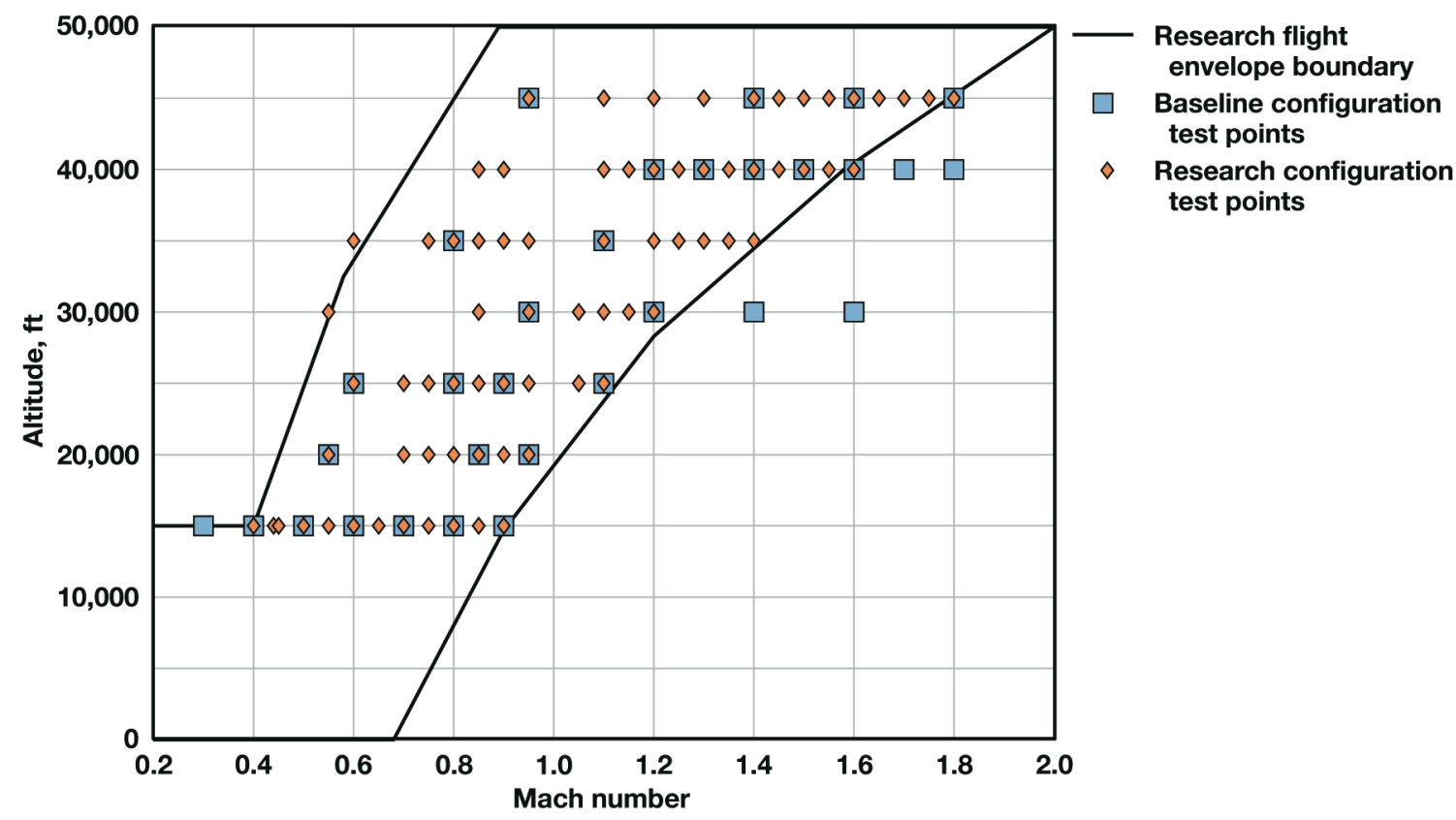

Figure 4. Experimental flight envelope and parameter estimation test conditions.

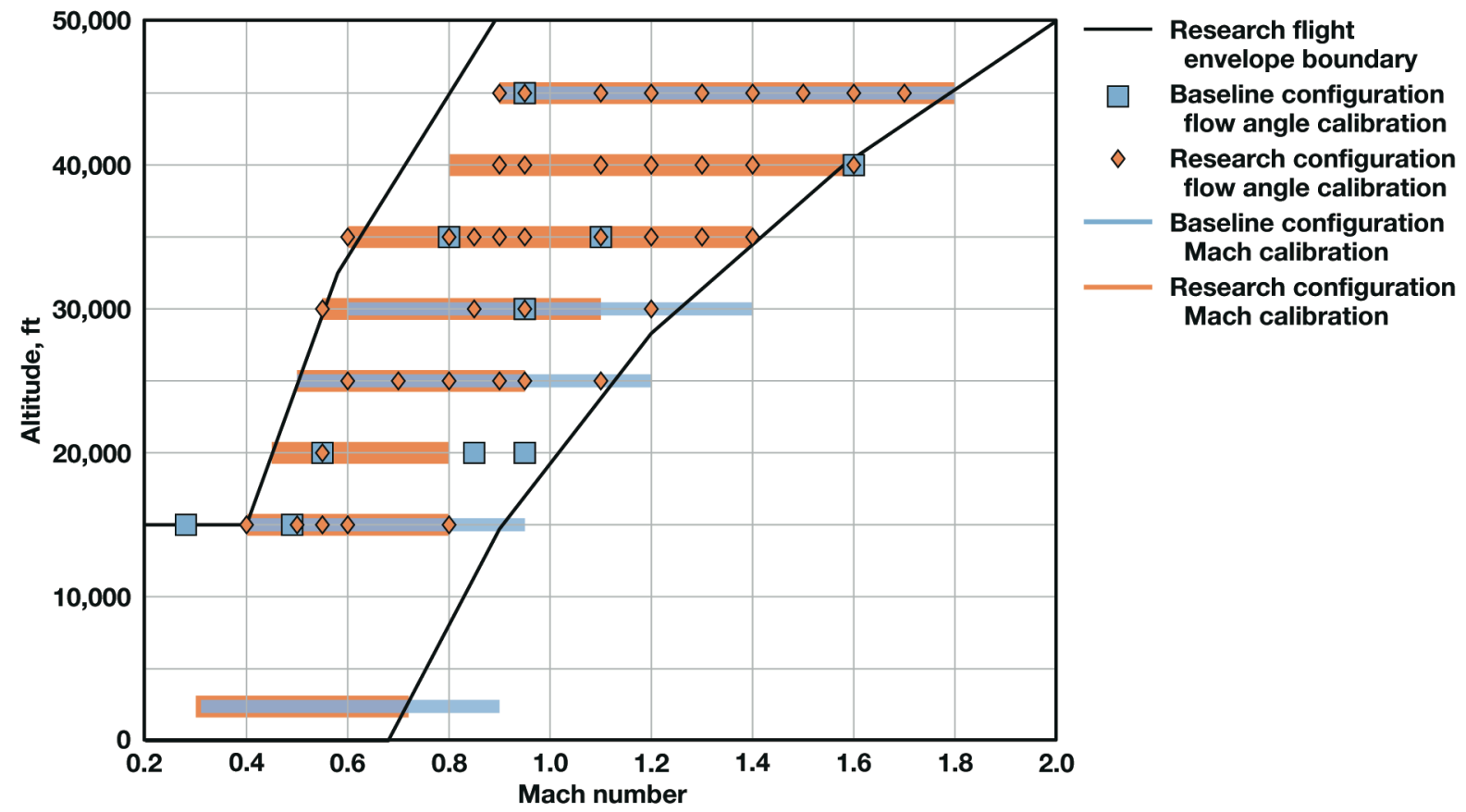

Figure 5. Experimental flight envelope and air data calibration flight conditions.

\section{Air Data Calibrations}

Because of concerns about air data errors associated with the influence of the experimental nose boom, a comprehensive plan for checking air data was created. During both the baseline and research flights, maneuvers were performed to characterize the aircraft air data parameters, including angle of attack, angle of sideslip, total pressure, and static pressure. 


\section{A. Pitot-Static Corrections}

The production pitot-static system was checked through a series of constant-altitude accelerations and constant-altitude decelerations. Airspeed measurements also were checked with a chase aircraft for in-flight system verification. The accelerations and decelerations were performed at multiple altitudes for various Mach number ranges. The acceleration maneuvers included tower flybys flown approximately $200 \mathrm{ft}$ above the ground past an instrumented tower. These flybys provided more accurate calibration data because of tower instrumentation. Meteorological data from sounding balloons and tower instrumentation were used to calculate freestream static pressure at the airplane flight altitude, which was provided by a differential GPS. This true static pressure was used along with data from the production pitot-static system to create static-position error correction curves. ${ }^{6}$

\section{B. Angle-of-Attack and Sideslip Calibrations}

Vehicle angle of attack and sideslip were calibrated using a combination of aircraft instrumentation and wind estimates. The maneuvers primarily used for calibration of angle of attack and sideslip were POPU maneuvers and rudder sweeps, respectively. Reference angle of attack and sideslip were derived from measured data. As the INS-GPS measured inertial velocity, wind data were required to produce air-relative speeds. Wind heading and magnitude were estimated using a combination of sounding balloons and 360-deg turns performed at altitude. Flow angles measured by the production air data system were then compared to the reference values to determine scale and bias errors. Typically, these errors are functions of Mach number and correction tables are constructed accordingly. ${ }^{6}$

\section{Aerodynamic Parameter Estimation}

Stability and control derivatives of the F-15B airplane for both flight series were obtained from flight data using standard parameter estimation techniques. ${ }^{7,8}$ For the baseline flights, the estimated stability and control derivatives were used to update the aerodynamic model in the six-degree-of-freedom simulation. The updating of the aerodynamic model took place after the baseline flight phase had been completed. For the research flights, simulation updates were performed as new parameter estimation results (for new flight conditions) were generated. The parameter estimation results also were used during envelope expansion to check stability and control derivative trends (for example, with Mach number) and validate simulation studies. These checks helped build confidence that the airplane would be safe to fly at the next flight condition.

Piloted doublets were the only maneuvers used for parameter estimation. Longitudinal axis derivatives were estimated using pitch doublets. Because no thrust measurements were available, lift and drag characteristics were not estimated. Lateral-directional derivatives were estimated using maneuvers that consisted of a yaw doublet immediately followed by a roll doublet. This maneuver style excited all of the necessary lateral-directional system responses and provided low levels of correlation between the control surface deflections. Maneuvers were typically performed in sets of three to provide repeatability. Cramér-Rao bounds, approximations of the estimated parameter variances, were used to provide a relative assessment of the accuracy of the results. ${ }^{7}$ Accuracy also was evaluated by comparing time histories of flight data to the output from the updated simulation.

\section{Effects on Air Data Systems}

The experimental nose boom did not impact the air data systems as severely as was initially expected. During the research flights, incremental adjustments were made to the baseline calibrations. When these adjustments were examined at the end of the flight series, however, many of the corrections fell within the uncertainty of the original calibrations.

\section{A. Effects on Pitot-Static System}

As expected, the experimental nose boom did affect the production pitot-static system, and changes to the static-position error corrections for the aircraft production pitot-static system were noted. The areas of the largest distinguishable change resulting from the experimental configuration occurred at high subsonic and high supersonic Mach numbers. Uncertainties in the transonic region created difficulty in discerning significant differences caused by the configuration. Figure 6 plots the difference between the baseline static correction curve and the correction curve in the experimental configuration from Mach 0.4 to 0.9. As Mach number increases towards the transonic region, the correction bias between the baseline and experimental configurations becomes more negative. Figure 7 shows the difference curve from Mach 1.4 to 1.8. The general trend is that the correction difference becomes larger 
as Mach number increases. Two Mach ranges are present, however, when the correction factor changes very little or has a trend that is less negative. These ranges are between Mach 1.46 and 1.6 and between Mach 1.7 and 1.8.

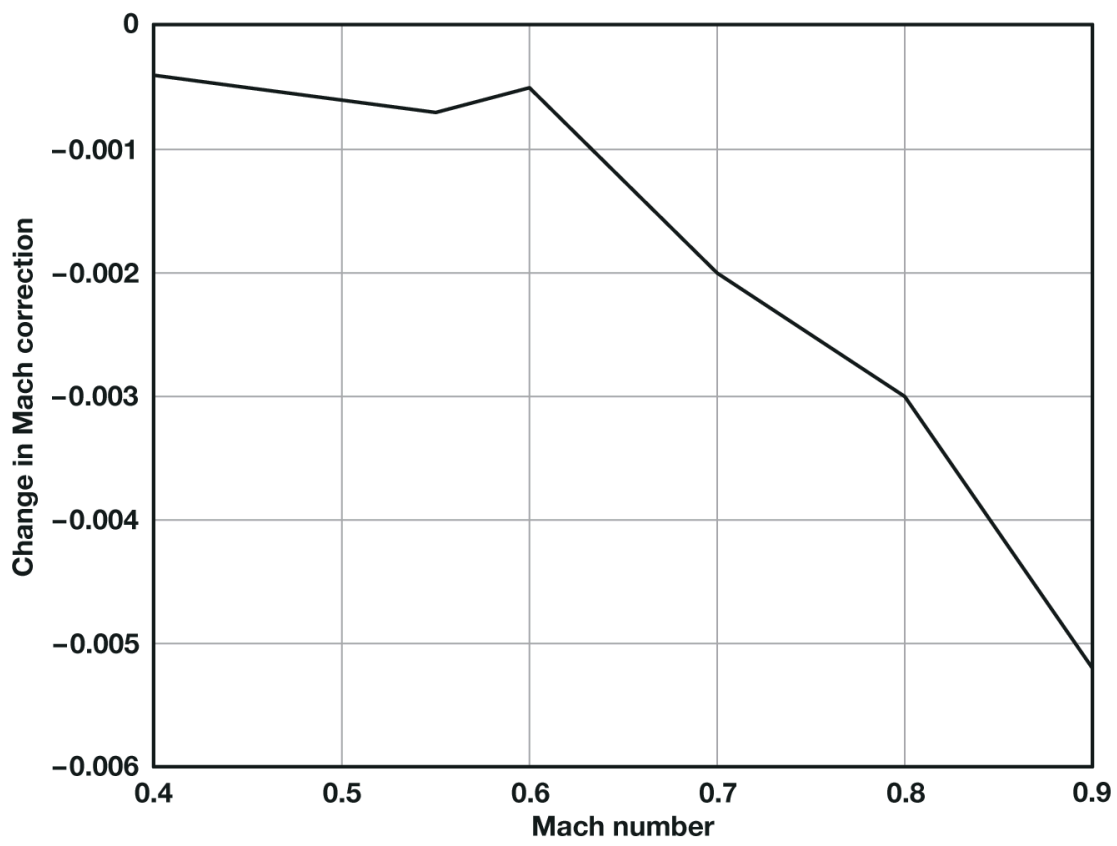

Figure 6. Subsonic static-position error resulting from experimental nose boom.

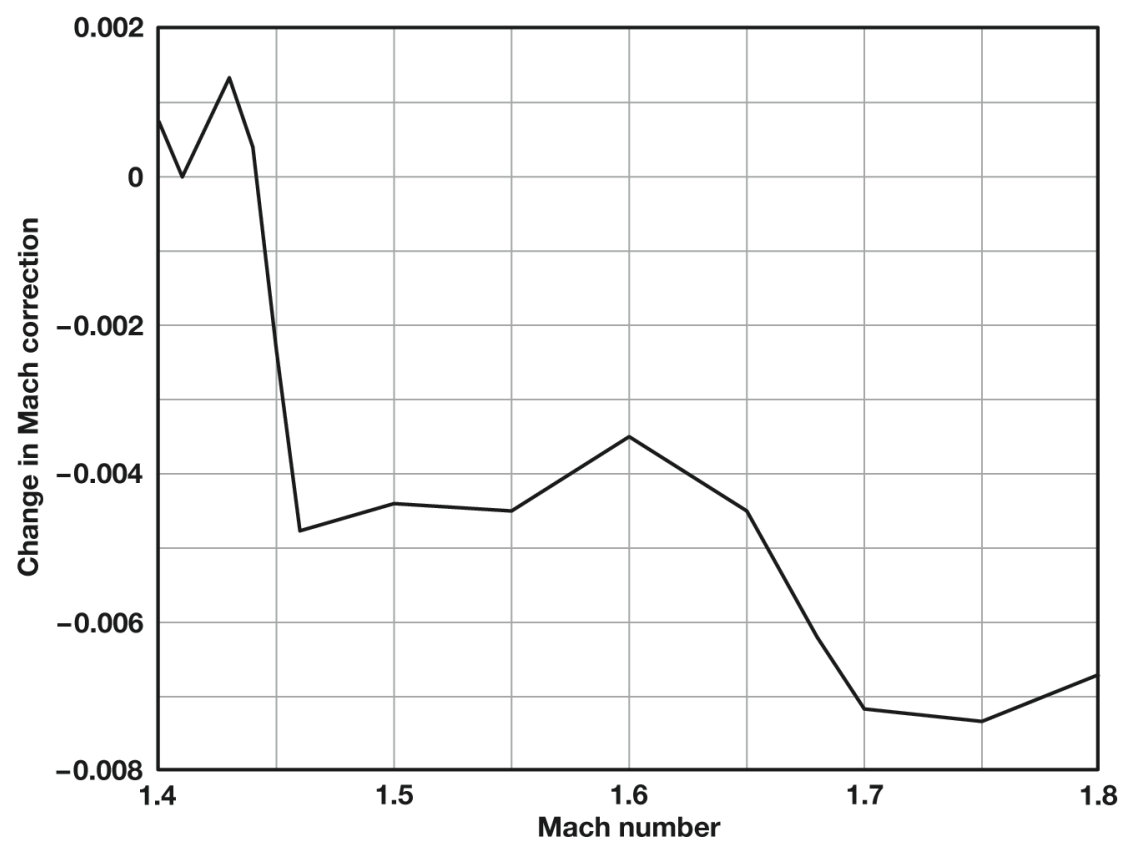

Figure 7. Supersonic static-position error resulting from experimental nose boom.

\section{B. Effects on Angle-of-Attack and Sideslip System}

Air flow sensors for angle of attack and sideslip were not significantly affected by the experimental nose boom. Throughout the research flights, maneuvers were performed and analyzed to check the baseline calibrations. Several 
updates were made to the calibrations during the flights, but when these calibrations were compared to the baseline maneuver data, they were found to be within the uncertainty of the original calibrations.

\section{Effects on Stability and Control}

Preliminary analyses predicted that the addition of the nose boom would negatively impact the stability of the F-15B airplane. Aerodynamic parameter estimation results confirmed that airplane stability was affected but not necessarily as predicted by the preliminary analyses. Damping derivatives, which were not included in the preliminary analyses, also appear to have been affected by the nose boom.

\section{A. Predicted Stability and Control Changes}

The principal results of the preliminary analyses were predicted changes to the stability derivatives of the F-15B airplane. Although the nose boom significantly altered the nose geometry of the airplane, it was not expected to generate significant forces on the airplane. Similarly, the nose boom was predicted to not significantly affect the aerodynamic force derivatives, $C_{L_{\alpha}}$ and $C_{Y_{\beta}}$. Figures 8 and 9 show the range of predictions for these derivatives produced from the various modeling efforts.

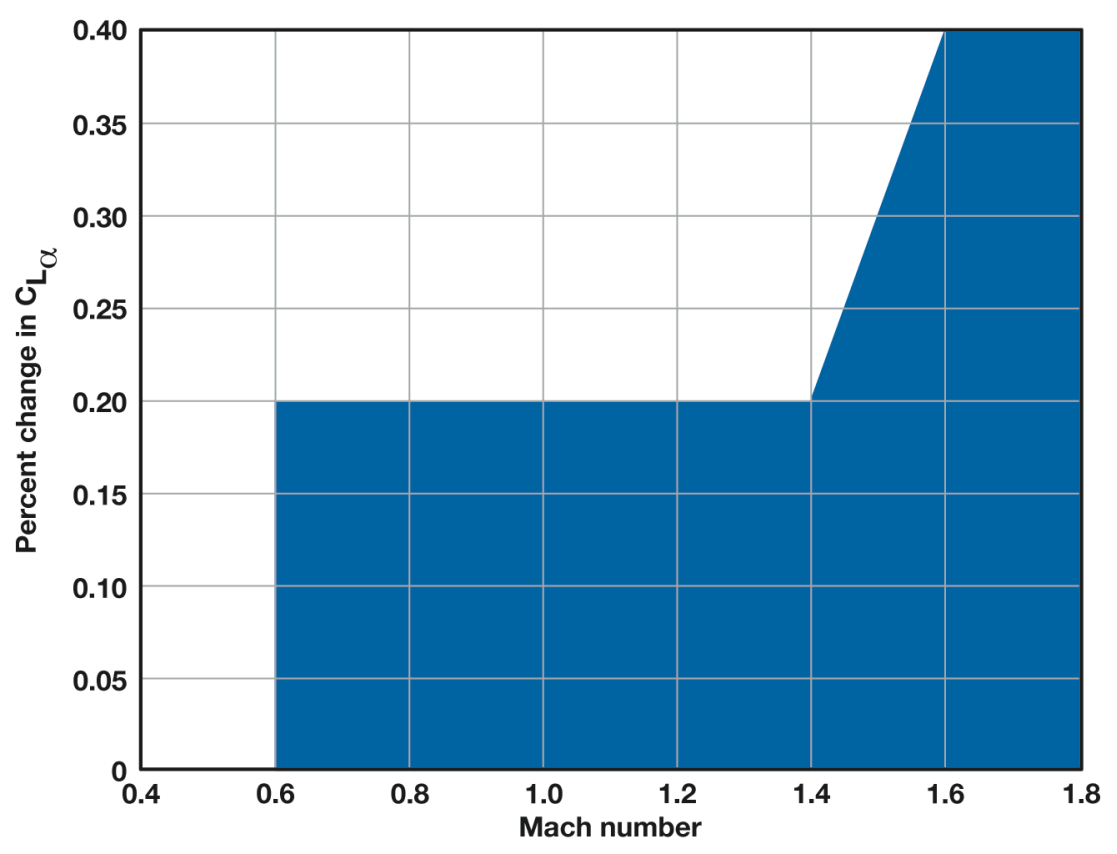

Figure 8. Predicted relative change in lift derivative. 


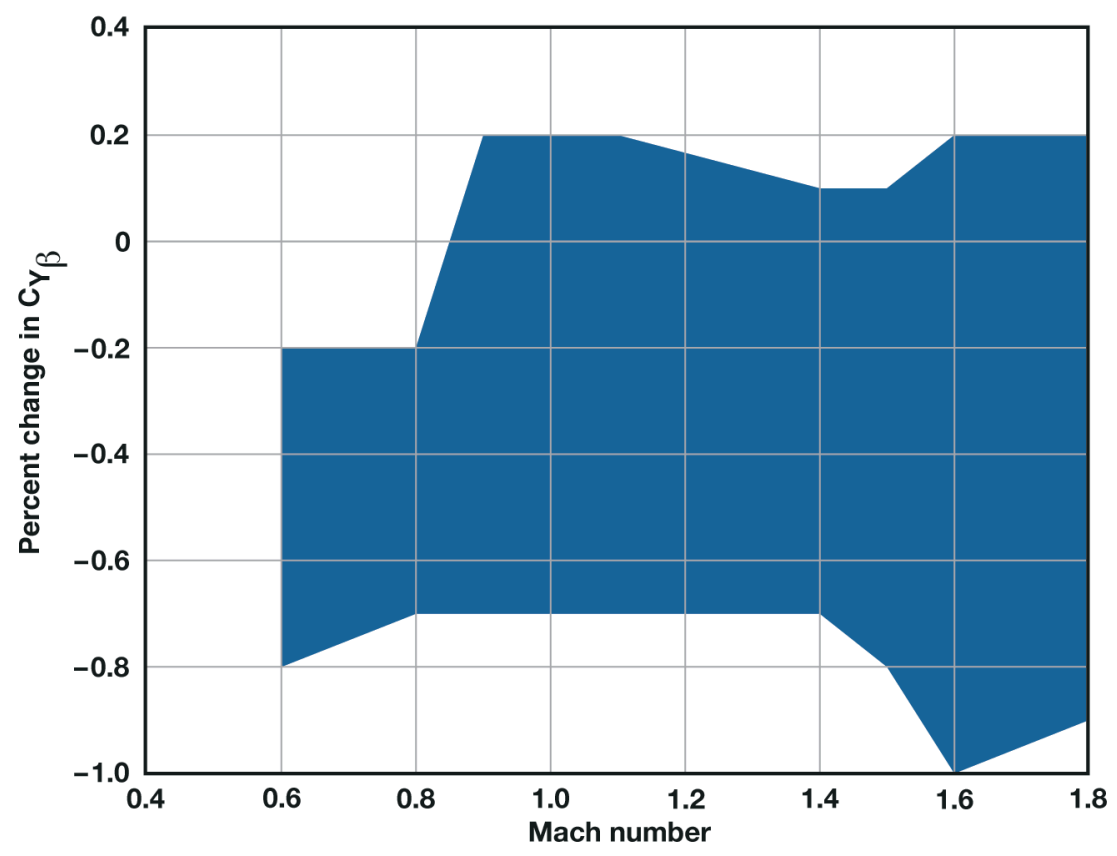

Figure 9. Predicted relative change in side force derivative.

Because of the size and placement of the experimental nose boom, it was expected to have an effect on the static pitch and yaw stability derivatives, $C_{m_{\alpha}}$ and $C_{n_{\beta}}$, respectively. Pitching moment due to angle of attack was predicted to become less stable with the addition of the nose boom. Because the F-15B airplane is very stable in pitch, however, the effect was predicted to be less than 10 percent for all flight conditions. Figure 10 shows the range of predictions for $C_{m_{\alpha}}$.

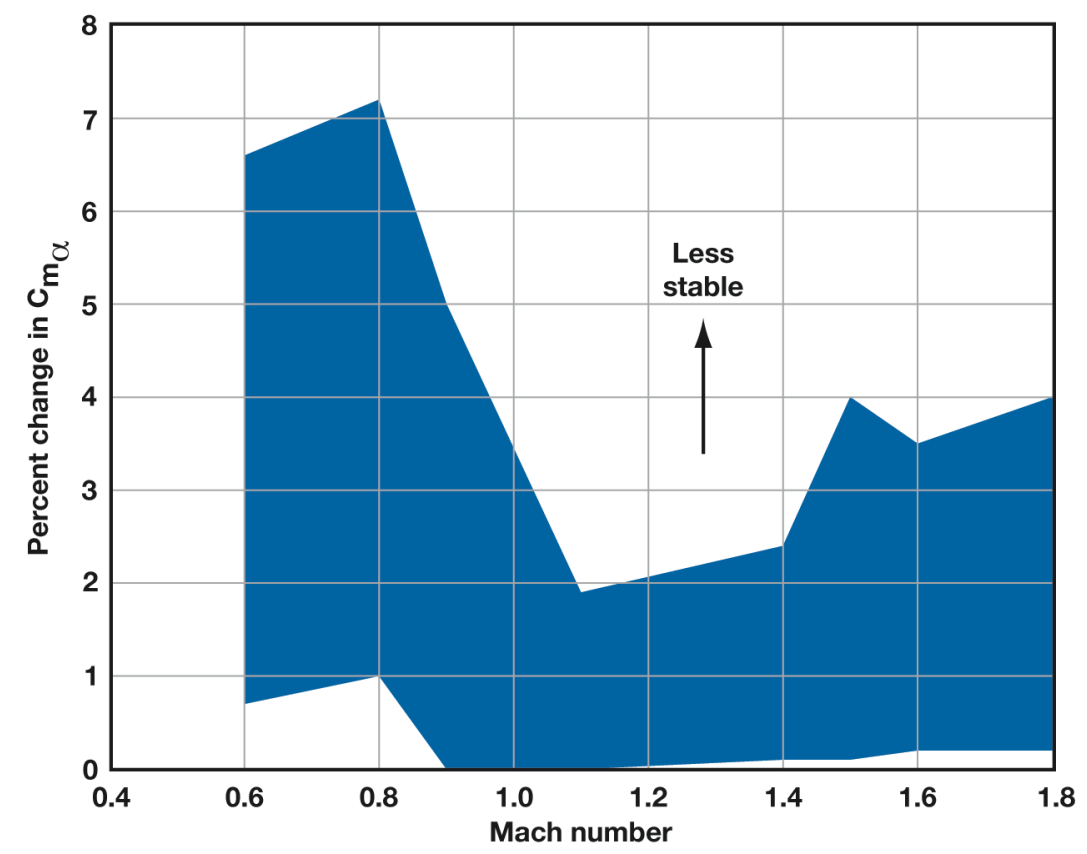

Figure 10. Predicted relative change in pitching moment derivative. 
The main concern for the research flights was a significant reduction in $C_{n \beta}$, particularly at high supersonic Mach numbers when the baseline airplane has reduced stability margins. Figure 11 shows the ranges of predictions for changes to $C_{n \beta}$. As the figure illustrates, the preliminary analysis predicted a reduction in stability of up to nearly 25 percent in the supersonic region. This area was the portion of the flight envelope in which the various preliminary analysis methods produced the widest range of predictions.

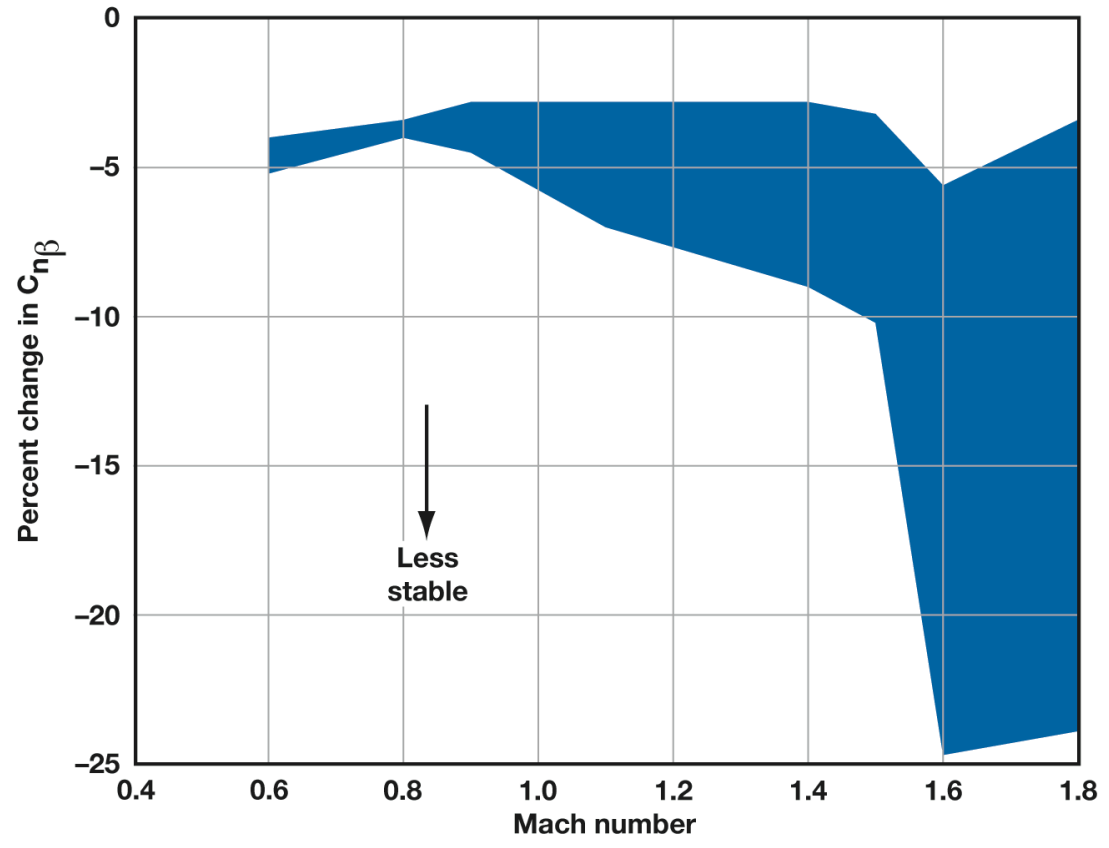

Figure 11. Predicted relative change in yawing moment derivative.

Uncertainties were created for all of the predicted changes to stability and control derivatives. These uncertainties were used for stability and controls analyses and are not included in this report. In addition to specific predictions of the effect of the experimental nose boom on stability and control, the possible influences of vortex shedding and associated asymmetries also were researched. This initial concern was shown to be highly improbable for the planned research flight regime.

\section{B. Parameter Estimation Results}

The parameter estimation results from both flight test series are generally good. Estimated system outputs (rates, accelerations, and so forth) match the flight data very well. Good agreement is typically shown within the sets of maneuvers performed at nearly each point. Scatter in the results is limited mostly to the transonic region or to cross derivatives such as yawing moment due to aileron, $C_{n_{d a}}$, or rolling moment due to nondimensional yaw rate, $C_{l_{r}}$. Cross-derivative terms are often difficult to estimate. Considerable scatter is seen in the estimates of the yaw damping derivative, $C_{n_{r}}$, but the results mostly fall within a band of roughly $0.2 \mathrm{deg}^{-1}$. Some derivatives show altitude dependence, particularly at supersonic speeds.

Comparisons with the baseline data show that the presence of the nose boom had little effect on most of the derivatives. In many cases, the differences between the two configurations are within the accuracy of the results. As predicted, the static stability derivatives of the F-15B airplane, $C_{m_{\alpha}}$ and $C_{n_{\beta}}$, were affected. The presence of the nose boom did not significantly affect $C_{Y_{\beta}}$, which is included in the predictions. Rolling moment due to sideslip, $C_{l_{\beta}}$, also was not affected by the nose boom. 
The pitch and yaw damping derivatives, $C_{m_{q}}$ and $C_{n_{r}}$, respectively, are not included in the preflight predictions. The flight results suggest that pitch damping, $C_{m_{q}}$, may have been reduced in the supersonic regime. Because of scatter and differences in flight conditions between the baseline and research flights, however, it cannot be decisively concluded that damping was reduced. Because of scatter in the $C_{n_{r}}$ estimates, changes in yaw damping resulting from the nose boom cannot be determined.

As previously mentioned, one of the derivatives of primary concern was the weathercock stability parameter, $C_{n \beta}$. Figure 12 shows the estimates of $C_{n_{\beta}}$ as a function of Mach number. The symbols represent the estimated values that produce the best match to the flight data when added to the six-degree-of-freedom simulation. Closed symbols are baseline aircraft results; open symbols are for the research configuration. The solid lines are trend lines through the baseline parameter estimation results. The dashed lines represent worst-case predictions, which are computed by applying derivative increments from the previously discussed preflight analyses to the baseline trends. The worst-case predictions do not include the uncertainties used in the preflight stability and control analysis.

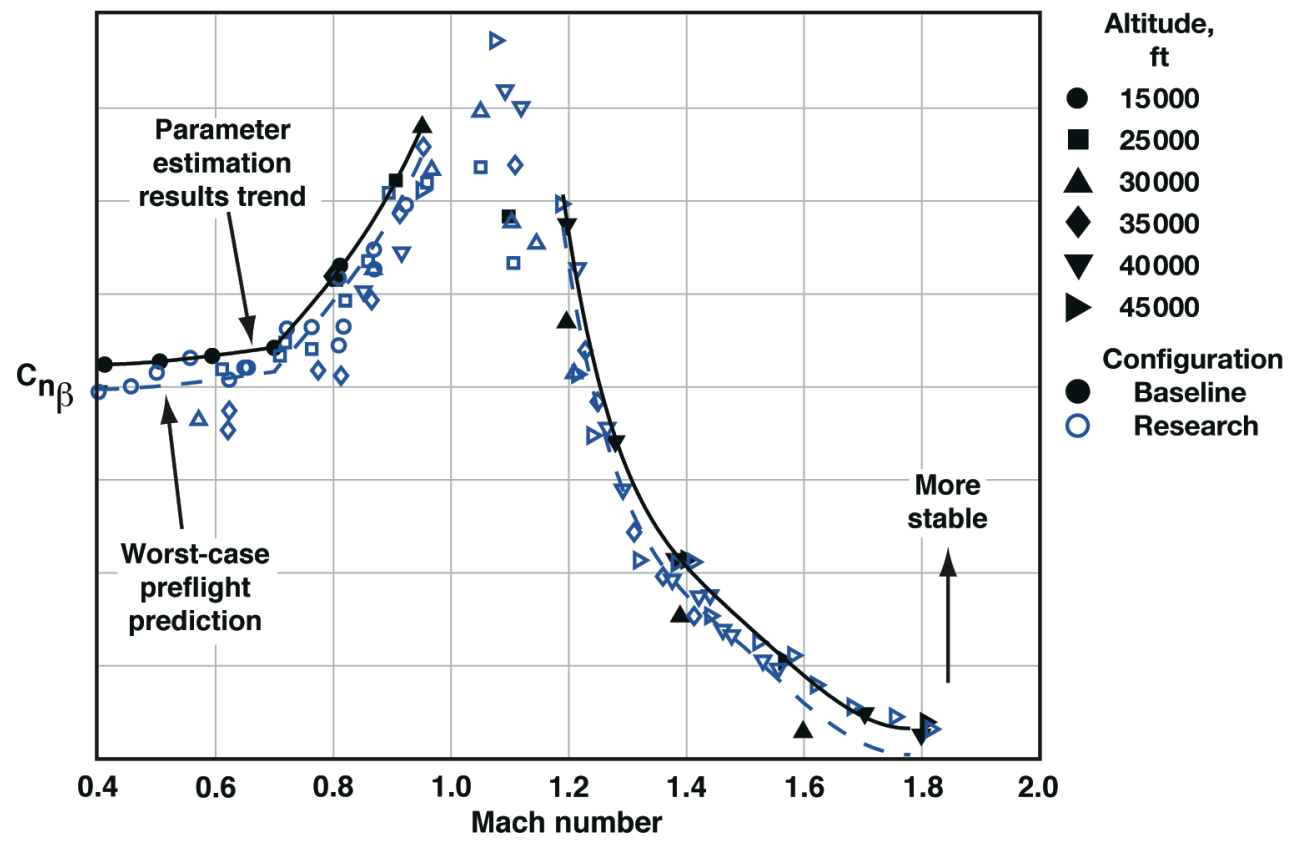

Figure 12. Estimated yawing moment due to sideslip angle for baseline and research configurations.

As predicted, the experimental nose boom had a destabilizing effect on $C_{n_{\beta}}$. As Fig. 12 shows, most of the changes occurred at subsonic speeds. In many cases, the estimates of $C_{n_{\beta}}$ are outside of the predicted range (that is, the flight results show that the nose boom was more destabilizing than predicted). Some of the maneuvers were flown at higher altitudes where no comparison data are available. Some of the reduction shown in $C_{n_{\beta}}$ might possibly be the result of an altitude effect. The nose boom did not reduce $C_{n \beta}$ at supersonic conditions as much as was predicted. Again, indications suggest that some altitude effects may be present.

Figure 13 shows the estimated values of the static pitch stability derivative, $C_{m_{\alpha}}$, using the same symbology as that used in Fig. 12. The three trend lines in the supersonic region represent baseline trends at altitudes of 30,000, 40,000, and 45,000 ft. As with $C_{n \beta}$, Fig. 13 shows that the experimental nose boom reduced stability in the subsonic region. Again, in many cases the reduction was greater than predicted. Some reduction in stability also can be seen in the supersonic region by comparing results on a per altitude basis. The figure is somewhat misleading, 
because no results are available for the research configuration faster than Mach 1.2 at an altitude of 30,000 ft. As a result, the $C_{m_{\alpha}}$ estimates appear to be bounded by the baseline trend.

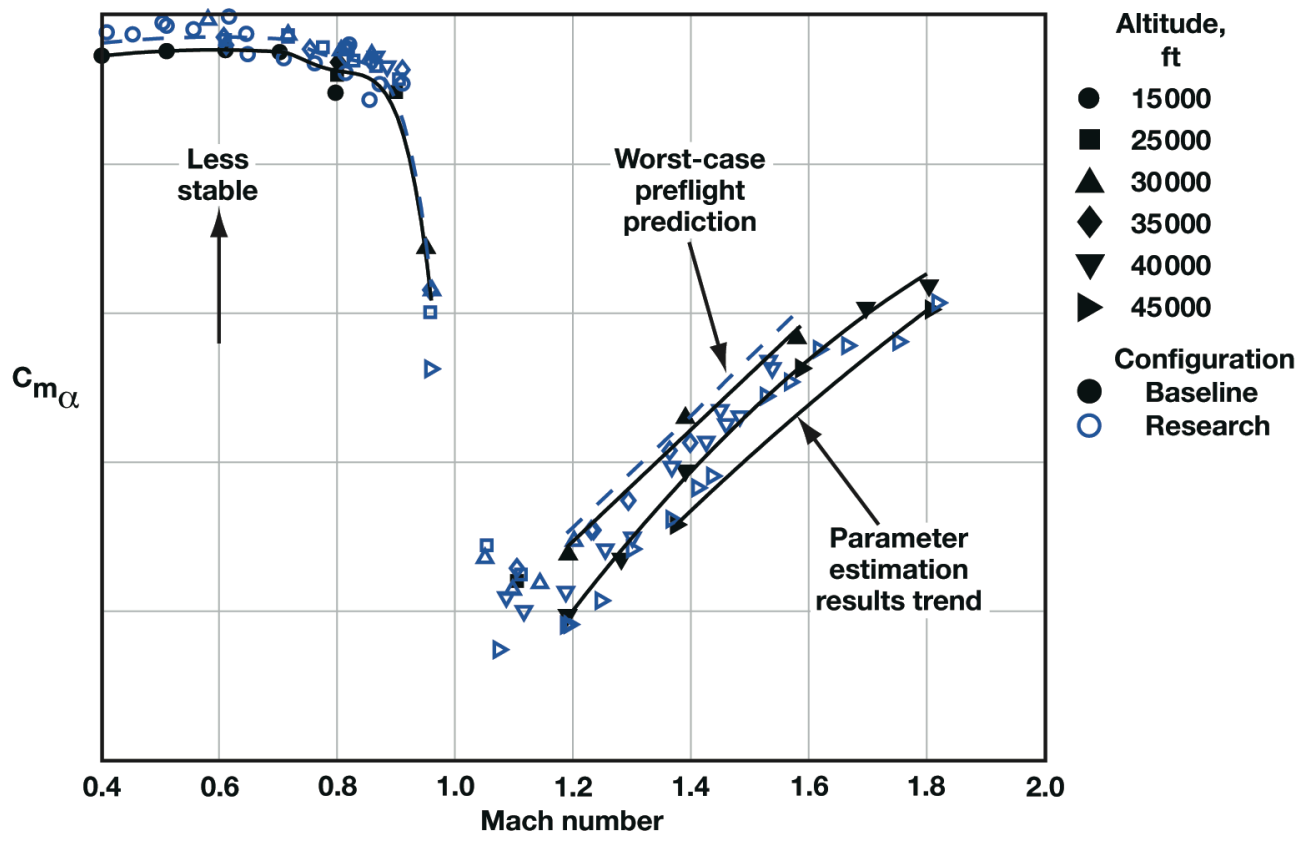

Figure 13. Estimated pitching moment due to angle of attack for baseline and research configurations.

\section{Validation of Aerodynamic Models}

The validity of any aerodynamic model is measured by its ability to accurately replicate flight data. The aerodynamic models created through parameter estimation were assessed based on this principle. When the models were completed, the F-15B simulation was updated appropriately. Maneuvers were then run through the simulation in an open-loop mode, in which flight-measured surface positions drove the control inputs. The output of the simulation was compared with the flight data to determine how well the aerodynamic model correlated with the flight data. Maneuvers used for this process included various types of doublets, rudder sweeps, POPU maneuvers, and windup turns. Coordinated maneuvers were predominantly used to assess the prediction capabilities of the model, because doublets were used to create it.

The baseline flight series was limited in scope and intended to update existing aerodynamic models. For the flight conditions in which data were taken, the baseline aerodynamic model updates produced reasonable matches with flight data. Figure 14 shows the longitudinal responses from a subsonic POPU maneuver from the baseline flight series. The agreement between flight and simulation responses is reasonable. Pitch rate matches well, whereas angle of attack and normal acceleration match reasonably for the majority of the maneuver. Figure 15 shows the lateral-directional responses from a supersonic rudder sweep maneuver from the baseline flights. The flight and simulation responses agree reasonably for this maneuver also. A discrepancy occurs in roll rate as the maneuver progresses, but it is not severe. Angle of sideslip, yaw rate, and lateral acceleration all match well. 
$\alpha$,

deg
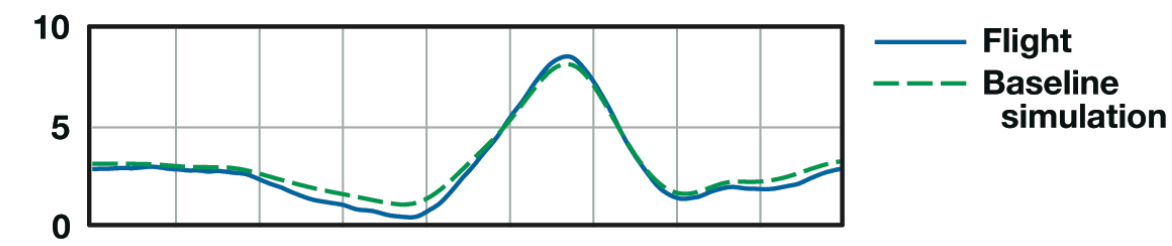

Pitch rate, deg/s

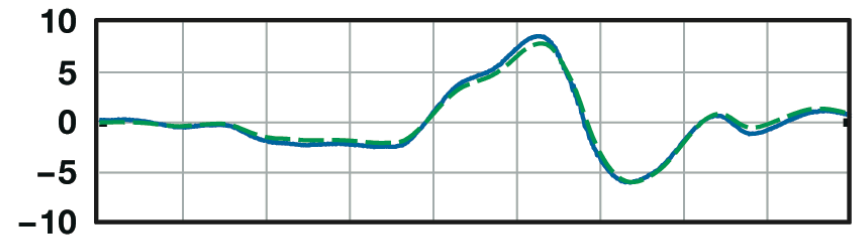

Normal acceleration,

g
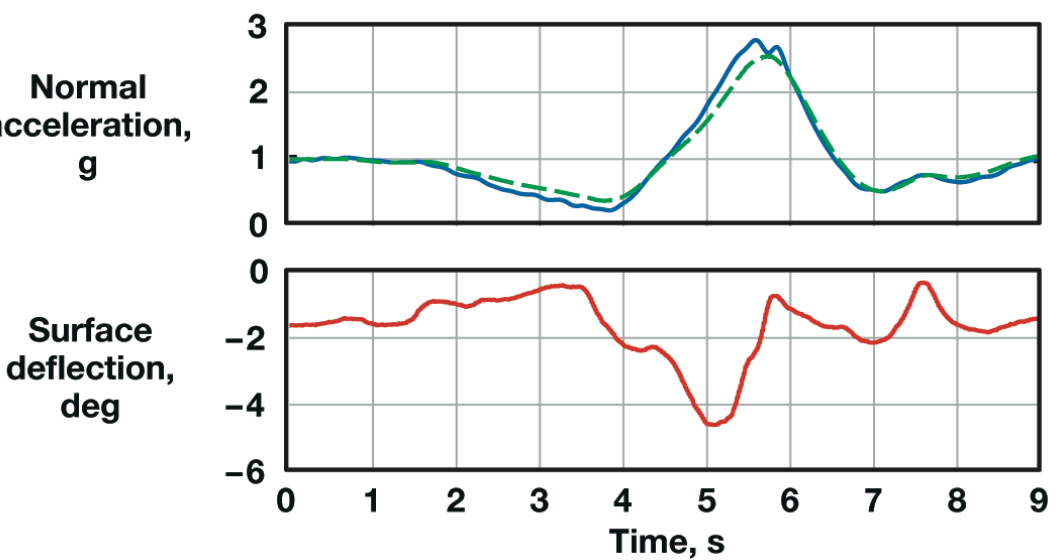

\section{Stabilator}

Figure 14. Longitudinal responses from a baseline flight subsonic push-over-pull-up maneuver.

$\beta$, deg

Roll rate, $\mathrm{deg} / \mathrm{s}$

Yaw rate, $\mathrm{deg} / \mathrm{s}$
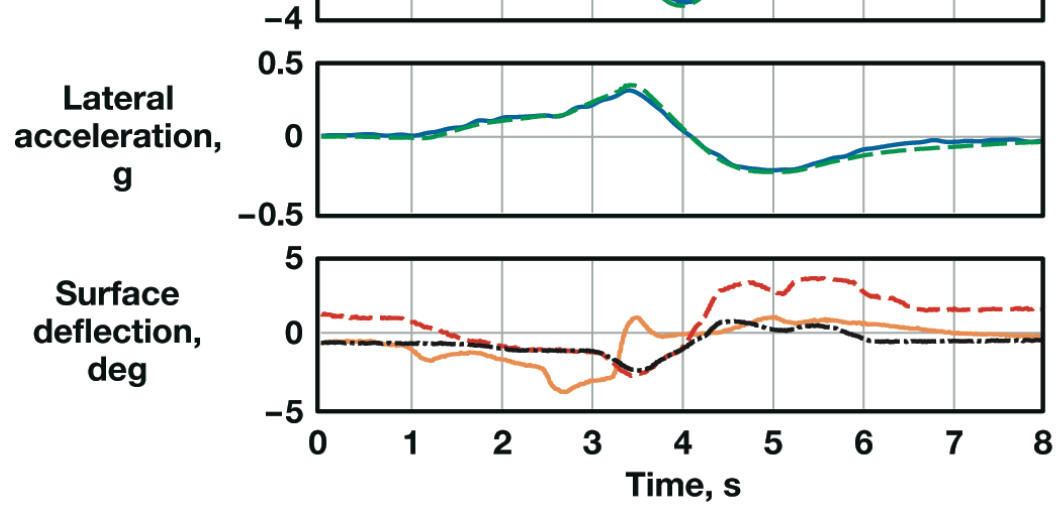

Flight

\section{Baseline
simulation \\ Baseline
simulation}

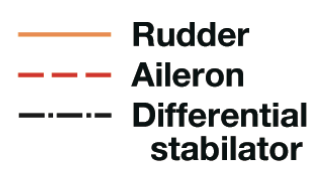

Figure 15. Lateral-directional responses from a baseline flight supersonic rudder sweep maneuver. 
Because of more extensive testing during the research flights, a more complete aerodynamic model was created for the experimental aircraft configuration. The test matrix for this series of flights covered the research envelope at a finer resolution than that of the baseline flights. Overall, the aerodynamic model created from these flights produced simulation results that match the flight data well.

At subsonic conditions, good agreement is shown in the responses for both longitudinal and lateral-directional maneuvers. Figure 16 shows the longitudinal responses from a subsonic POPU maneuver from the research flights. Angle of attack, pitch rate, and normal acceleration show good agreement between the flight and simulation. Figure 17 shows the lateral-directional responses from a subsonic rudder sweep maneuver. The agreement for angle of sideslip and lateral acceleration is reasonable. Yaw rate matches well. The roll rates agree reasonably well for the majority of the maneuver, considering that the maneuver contained minimal roll excitation.

$\alpha$ deg
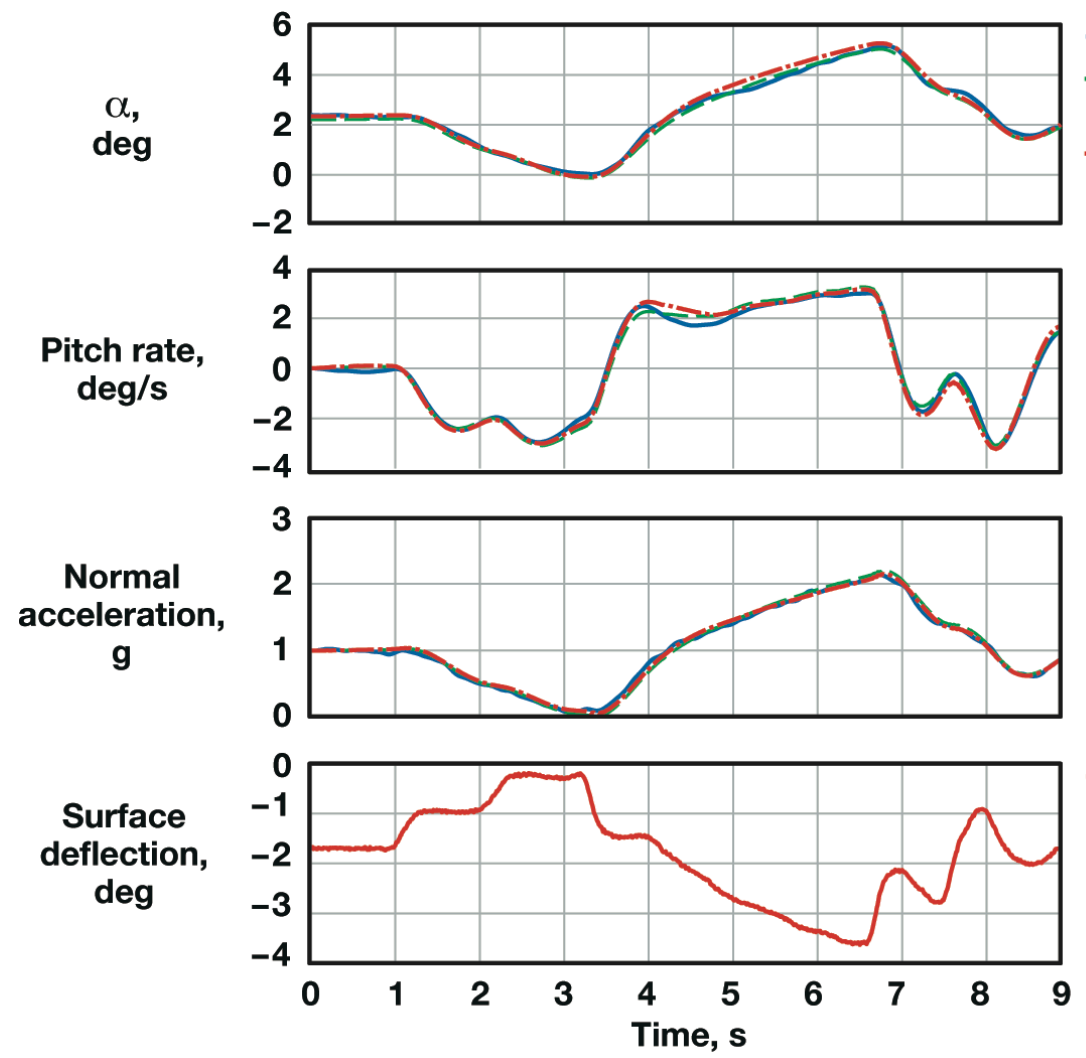

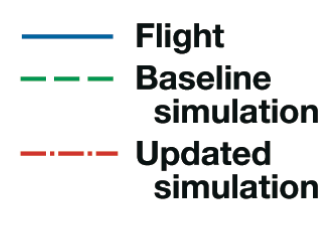

\section{Stabilator}

Figure 16. Longitudinal responses from a research flight subsonic push-over-pull-up maneuver. 


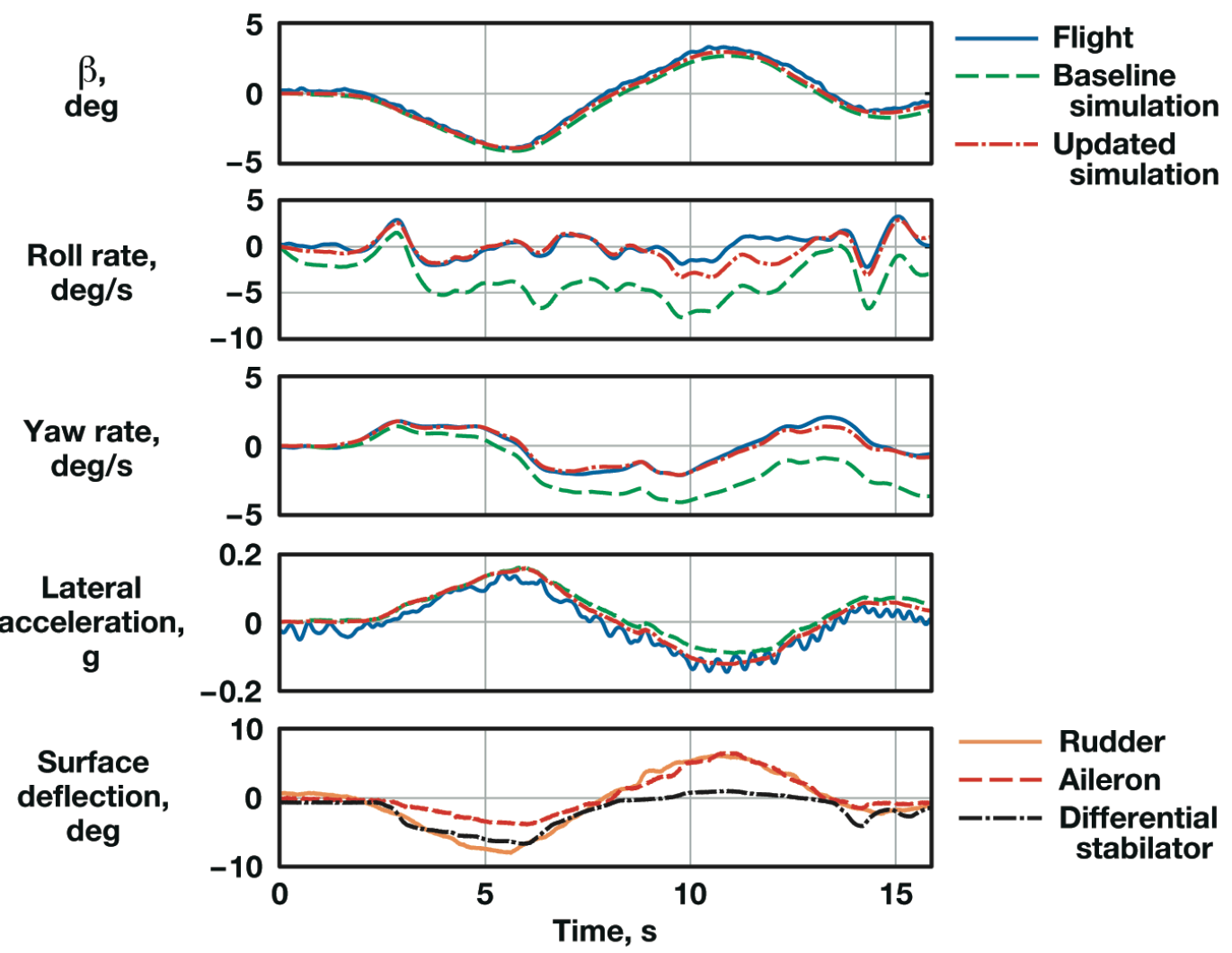

Figure 17. Lateral-directional responses from a research flight subsonic rudder sweep maneuver.

For maneuvers flown at supersonic flight conditions, agreement between the flight data and results from the updated simulation also are reasonable. Figure 18 shows the longitudinal responses from a supersonic POPU maneuver. Flight and simulation responses agree well for angle of attack, pitch rate, and normal acceleration. Figure 19 shows the lateral-directional responses from a supersonic rudder sweep maneuver. Angle of sideslip matches well throughout the maneuver, as does lateral acceleration. Yaw rate also matches well. A small difference occurs in roll rates, but the agreement is still reasonable for a rudder sweep. 
$\alpha$,

deg
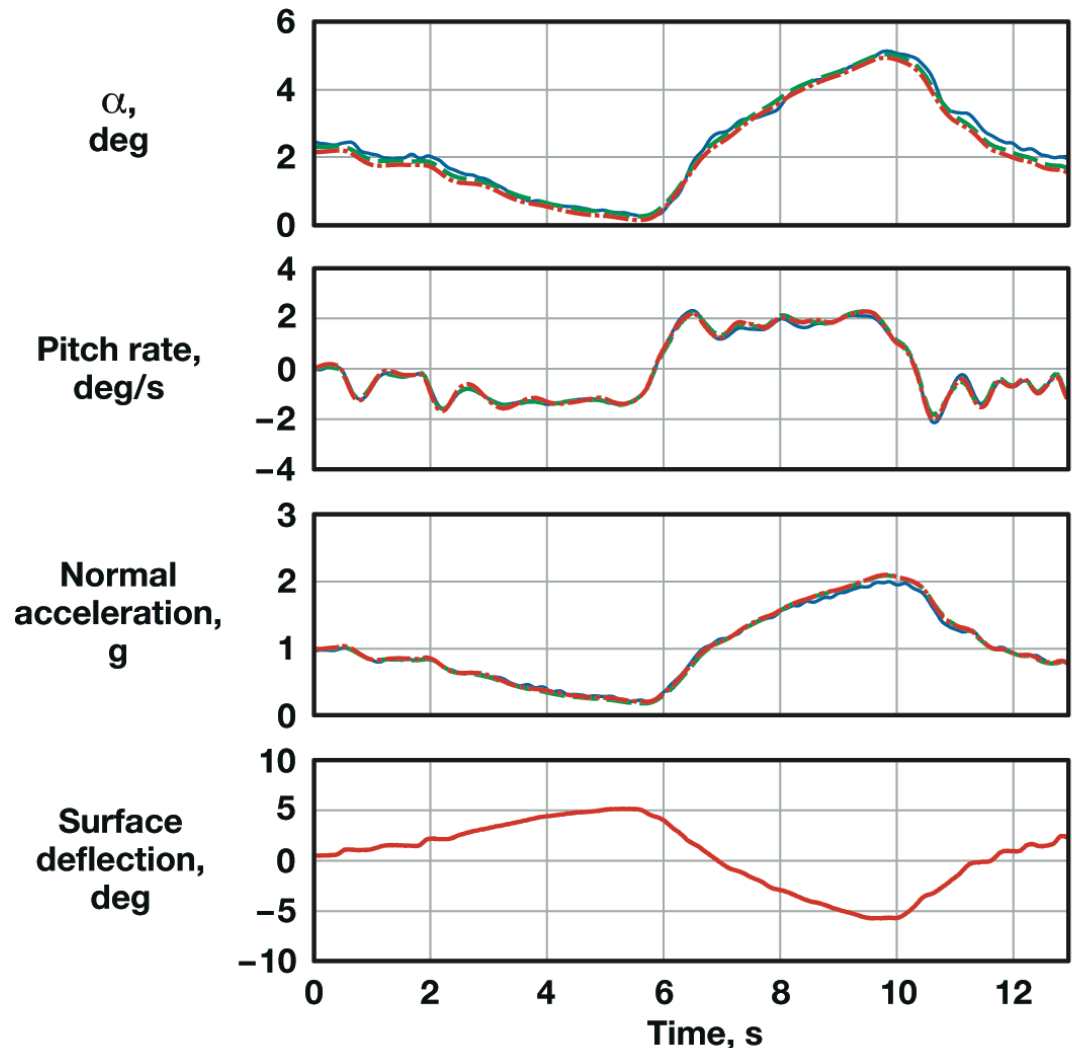

Flight

- - - Baseline simulation

Updated simulation

\section{Stabilator}

Figure 18. Longitudinal responses from a research flight supersonic push-over-pull-up maneuver.

$\beta$, $\operatorname{deg}$

Roll rate, $\mathrm{deg} / \mathrm{s}$

$$
\begin{array}{r}
5 \\
0 \\
-5
\end{array}
$$

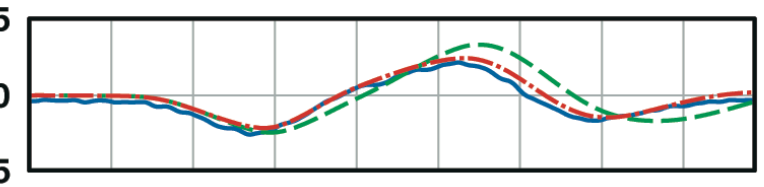

$$
\begin{array}{r}
10 \\
0 \\
-10 \\
-20
\end{array}
$$
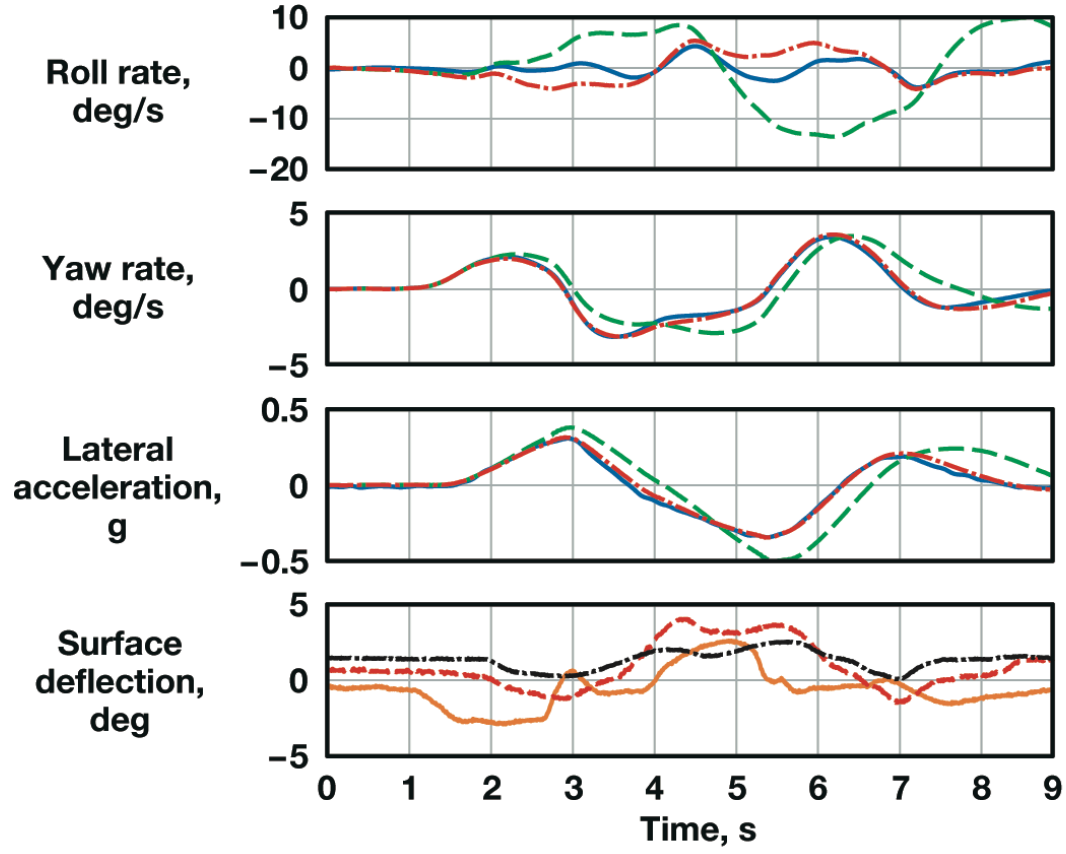

Flight

Baseline simulation

Updated simulation

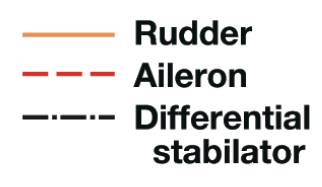

Figure 19. Lateral-directional responses from a research flight supersonic rudder sweep maneuver. 
In the transonic region, the agreement for the responses from the lateral-directional maneuvers is not consistent. Rudder sweeps near the transonic region were particularly difficult to reproduce accurately in the simulation. Yaw and roll axes doublets did not display this issue, nor did any longitudinal maneuvers. Whether this problem was caused by inaccuracies in the modeling or problems in the simulation itself is not known.

\section{Conclusion}

An experimental 24-ft, multisegmented telescoping nose boom, designed for sonic boom research, was installed and successfully flown on an F-15B airplane. Initial predictions indicated the possibility of significant aerodynamic effects resulting from the experimental nose boom. Preflight analyses, including computational fluid dynamics studies, predicted that the boom would have a destabilizing effect on the pitching moment coefficient due to angle of attack, $C_{m_{\alpha}}$, and the yawing moment coefficient due to angle of sideslip, $C_{n_{\beta}}$. Of primary concern were predictions that $C_{n \beta}$ would be significantly reduced at high speeds when margins are already small for the baseline F-15B airplane. Another concern was that the oversized nose boom could affect the air data measurements of the airplane.

Analysis of flight data showed that the experimental nose boom did affect the F-15B airplane. As predicted, static pitch and yaw stability were reduced. At supersonic speeds, however, yaw stability was not diminished as much as preflight predictions had suggested. As predicted, the experimental nose boom also affected the air data system. Although no significant effects on angle-of-attack or angle-of-sideslip measurements were determined, the static-position error was affected. The effects were noticeable through much of the subsonic flight regime and through the upper part of the supersonic flight regime. The project was successfully completed, and the F-15B airplane was flown safely and without incident through a large portion of the flight envelope.

\section{References}

${ }^{1}$ Richwine, D.M., “F-15B/Flight Test Fixture II: A Test Bed for Flight Research,” NASA TM-4782, 1996.

${ }^{2}$ Richwine, D.M., and Del Frate, J.H., "Development of a Low-Aspect Ratio Fin for Flight Research Experiments," NASA TM-4596, 1994.

${ }^{3}$ Smith, M.S., "Photogrammetric Trajectory Estimation of Foam Debris Ejected From an F-15 Aircraft," NASA TM-2006213675,2006

${ }^{4}$ Hoerner S.F., Fluid-Dynamic Drag, Hoerner Fluid Dynamics, Vancouver, Washington, 1965.

${ }^{5}$ Muraca, R.J., "An Empirical Method for Determining Static Distributed Aerodynamic Loads on Axisymmetric Multistage Launch Vehicles," NASA TN D-3283, 1966.

${ }^{6}$ Haering, E.A., Jr., "Airdata Calibration of a High-Performance Aircraft for Measuring Atmospheric Wind Profiles,” NASA TM-101714, 1990.

${ }^{7}$ Maine, R.E., and Iliff, K.W., “Application of Parameter Estimation to Aircraft Stability and Control: The Output-Error Approach,” NASA RP-1168, 1986.

${ }^{8}$ Murray, J.E., and Maine, R.E., “pEst Version 2.1 User’s Manual,” NASA TM-88280, 1987. 